\title{
Interprofessional Role Clarity, Case-Based Learning, and Perceptions of Group Effectiveness Among Athletic Training and Physical Therapy Students in a Shared Professional Course
}

Katie Sniffen

Saint Louis University, katie.sniffen@health.slu.edu

Erick Briggs

Saint Louis University, erick.briggs@slu.edu

Leslie Hinyard

Saint Louis University, leslie.hinyard@health.slu.edu

Anthony P. Breitbach

Saint Louis University, anthony.breitbach@health.slu.edu

Follow this and additional works at: https://nsuworks.nova.edu/ijahsp

Part of the Interprofessional Education Commons, and the Other Rehabilitation and Therapy Commons

This Manuscript has supplementary content. View the full record on NSUWorks here: https://nsuworks.nova.edu/ijahsp/vol17/iss4/6

\section{Recommended Citation}

Sniffen K, Briggs E, Hinyard L, Breitbach AP. Interprofessional Role Clarity, Case-Based Learning, and Perceptions of Group Effectiveness Among Athletic Training and Physical Therapy Students in a Shared Professional Course. The Internet Journal of Allied Health Sciences and Practice. 2019 Jan 01;17(4), Article 6.

This Manuscript is brought to you for free and open access by the College of Health Care Sciences at NSUWorks. It has been accepted for inclusion in Internet Journal of Allied Health Sciences and Practice by an authorized editor of NSUWorks. For more information, please contact nsuworks@nova.edu. 


\title{
Interprofessional Role Clarity, Case-Based Learning, and Perceptions of Group Effectiveness Among Athletic Training and Physical Therapy Students in a Shared Professional Course
}

\begin{abstract}
Purpose: Health professions students experience professional socialization during their program of study. Institutions have turned to interprofessional education as a means of preparing students for their role as collaborative health care professionals. This study examines the effect of case-based learning experiences in a shared professional Therapeutic Modalities course on student's interprofessional role clarity as well as the relationship between interprofessional role clarity and measure of group effectiveness. Methods: 112 students (22 Athletic Training and 90 Physical Therapy) were assigned to one of 18 interprofessional and 18 uniprofessional teams and asked to complete four case-based learning activities. All students completed pre-test, retrospective pre-test, and post-test role clarity/ambiguity scales. Measures of team viability, team member satisfaction, and self-rated output were collected post-intervention. Results: Results suggest the experience of interacting with one another in this course, including during case-based learning activities, may lead to increased knowledge of other's roles and responsibilities as shown in the retrospective pre-test and post-test role clarity differences. Additionally, role clarity has meaningful relationships with measures of perceived group effectiveness, particularly team viability and self-rated output. Conclusion: We suggest that health professions educators consider incorporating case-based learning activities into existing curricula to introduce other professions' roles and engage students in teamwork.
\end{abstract}

\section{Author Bio(s)}

Katie Sniffen, MS, ATC is the Clinical Coordinator for Saint Louis University's Center for Interprofessional Education and Research and adjunct faculty in SLU's Physical Therapy and Athletic Training Department. Ms. Sniffen is also a first-year doctoral student in Public Health Studies, with a concentration in Health Outcomes Research.

Erick Briggs, MS is a doctoral student in Saint Louis University's Industrial/Organizational Psychology program. Erick's research interests include family relationships in the workplace, team processes, high stakes contexts, and cross-cultural management. He also has applied experience in telecommunications, sales, and consulting.

Dr. Leslie Hinyard, PhD, MSW is the Deputy Director and Associate Professor of the Saint Louis University Center for Health Outcomes Research. Her research interests include racial disparities in women with breast cancer and the role of interprofessional collaborative practice in improving care processes and health outcomes.

Dr. Anthony Breitbach, PhD, ATC is the Director of the Athletic Training Program at Saint Louis University. He serves a variety of roles for the Association of Schools of Allied Health Professions, Interprofessional Education Collaborative Council, American Interprofessional Health Collaborative, and the Journal of Interprofessional Care.

\section{Acknowledgements}

None 


\title{
TJAHSP-
}

The Internet Journal of Allied Health Sciences and Practice

Dedicated to allied health professional practice and education

Vol. 17 No. 4 ISSN 1540-580X

\section{Interprofessional Role Clarity, Case-based Learning, and Perceptions of Group Effectiveness Among Athletic Training and Physical Therapy Students in a Shared Professional Course}

\author{
Katie Sniffen \\ Erick Briggs \\ Leslie Hinyard \\ Anthony P. Breitbach \\ Saint Louis University \\ United States
}

\begin{abstract}
Purpose: Health professions students experience professional socialization during their program of study. Institutions have turned to interprofessional education as a means of preparing students for their role as collaborative health care professionals. This study examines the effect of case-based learning experiences in a shared professional therapeutic modalities course on students' interprofessional role clarity as well as the relationship between interprofessional role clarity and measure of group effectiveness. Methods: One hundred twelve (112) students (22 athletic training and 90 physical therapy) were assigned to one of 18 interprofessional and 18 uni-professional teams and asked to complete four case-based learning activities. All students completed pre-test, retrospective pre-test, and post-test role clarity/ambiguity scales. Measures of team viability, team member satisfaction, and self-rated output were collected post-intervention. Results: Results suggest the experience of interacting with one another in this course, including during case-based learning activities, may lead to increased knowledge of others' roles and responsibilities as shown in the retrospective pre-test and post-test role clarity differences. Additionally, role clarity has meaningful relationships with measures of perceived group effectiveness, particularly team viability and self-rated output. Conclusion: We suggest that health professions educators consider incorporating case-based learning activities into existing curricula to introduce other professions' roles and engage students in teamwork.
\end{abstract}

Keywords: health professions education, athletic training, physical therapy, case-based learning, role clarity, group effectiveness 


\section{INTRODUCTION}

Health professionals have a responsibility to fulfill a social contract with society where they are expected to serve as both healers and professionals. ${ }^{1}$ Educational programs look to prepare health professions students for this responsibility as they experience professional socialization during their program of study. This socialization is impacted by the progressive development of expectations regarding one's professional roles and responsibilities throughout their clinical and educational experiences. ${ }^{2}$ Institutions have turned to interprofessional education (IPE) as a means of preparing students for their role as health professionals. The World Health Organization (WHO) has defined IPE as learning that "occurs when students from two or more professions learn about, from, and with each other to enable effective collaboration and improve health outcomes." ${ }^{3}$ IPE experiences allow students to gain knowledge about their professional roles and the roles of others in the context of team-based health care. ${ }^{4-7}$ There has been an effort to embed authentic interprofessional learning experiences in formal professional program courses. 8,9

The primary objective of this study is to examine the extent to which interprofessional role clarity could be enhanced by implementing a set of case-based learning experiences into a professional program course. The secondary objective of this study is to examine, at the individual level, the relationship between interprofessional role clarity and perceptions regarding individuals' experiences of working within their case study teams; specifically, perceptions regarding team viability, team member satisfaction, and self-rated output are examined.

\section{Background}

The theoretical framework guiding this study is based on research examining the design of work teams and the model of group effectiveness described by Hackman. ${ }^{10}$ This framework considers group effectiveness based on the three criteria of output, viability, and individual group member satisfaction. The output criterion refers to the extent to which the group's work meets or exceeds standards, viability refers to the extent to which the social processes group members use to carry out work enhance the potential for group members to work well together in the future, and individual group member satisfaction refers to the extent to which the collaborative experience satisfies the needs of individual group members. Group members who collaborate in a manner that hinders future collaboration cannot be considered most effective. Similarly, when collaborative experiences result in disgust and disillusionment among individual group members, then the costs may outweigh the potential benefits of group work. ${ }^{10} \mathrm{~A}$ visual representation of this framework is presented in Figure 1.

\section{Input}

Process

Output

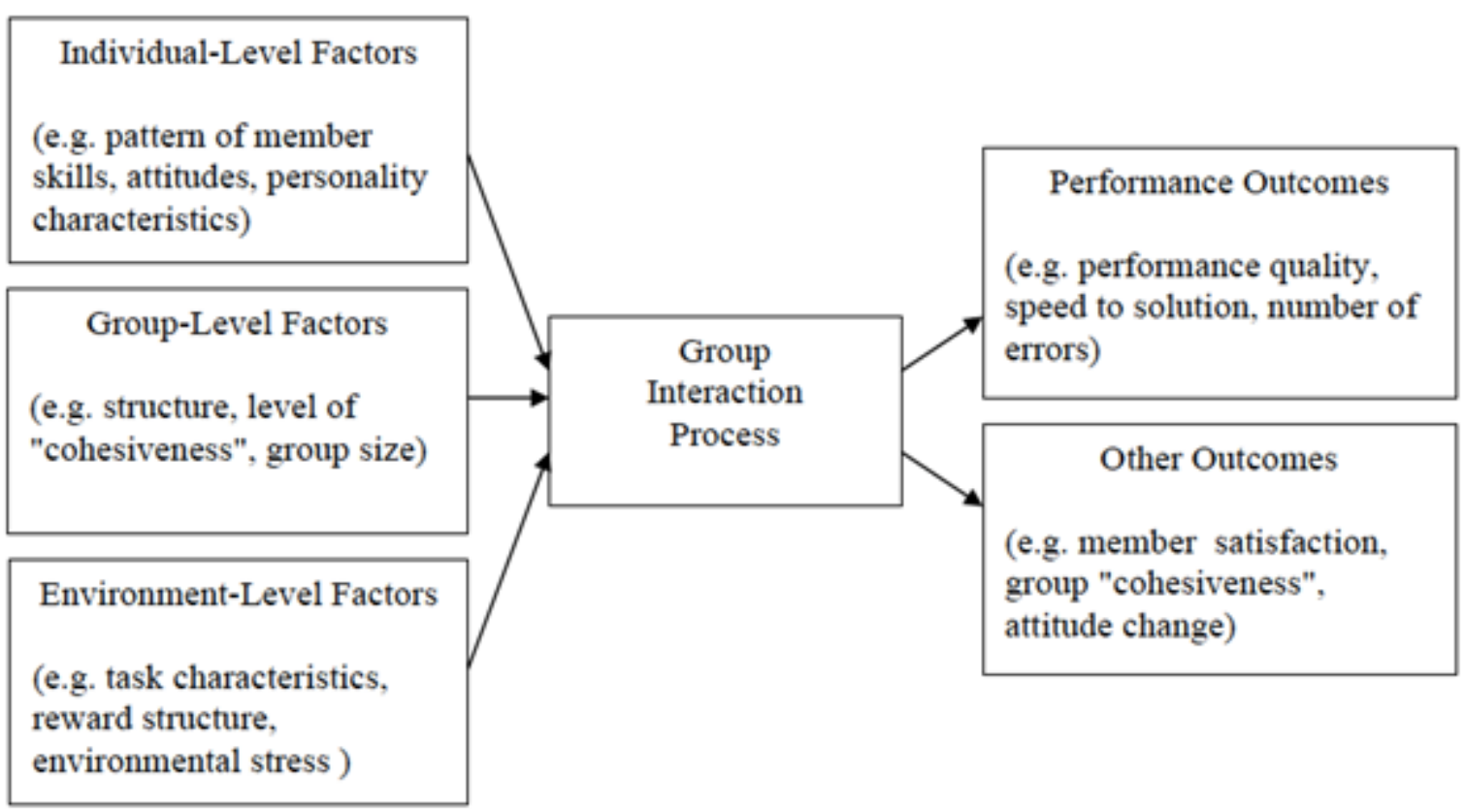

Figure 1. Model of Group Effectiveness 
Hackman argues that the extent to which groups meet effectiveness criteria depends largely upon the effort, performance strategies, and the knowledge and skills of group members, which are all considered process criteria. Moreover, Hackman's framework posits that inputs including group design, organizational context, and group synergy all impact the process criteria described above. ${ }^{10}$ Our study hones in on one particular part of this framework - the knowledge components of process criteria, and its link to group design. More specifically, we focus on the relationship between the knowledge group members possess regarding each other's roles and group design. To summarize, we use the theoretical framework of work team design and group effectiveness to examine the extent to which group effectiveness is influenced by group diversity (single or multi-professional) and group member knowledge (knowledge of professional roles).

A secondary aim is to examine the effectiveness of a case-based learning intervention aimed to enhance understanding of rolerelated contingencies across professional boundaries. Case-based learning interventions include problem-based and case-based learning activities as examples of ways to facilitate student learning by working in groups to address traditional medical practice problems. ${ }^{11}$ Existing literature supports the use of interprofessional case-based exercises to improve role clarity. ${ }_{6}, 7,12$ We hypothesize:

H1: Compared to pre-test role clarity scores, post-test role clarity scores are expected to be significantly higher.

H2: Compared to retrospective pre-test role clarity scores, post-test role clarity scores are expected to be significantly higher.

H3: Differences between pre-test role clarity scores and post-test role clarity scores will be greater for individuals in the interprofessional group condition, compared to those in the uni-professional group condition

H4: Differences between retrospective pre-test role clarity scores and post-test role clarity scores will be greater for individuals in the interprofessional group condition, compared to those in the uni-professional group condition.

H5: Interprofessional role clarity will be positively related to perceptions of team viability, individual team member satisfaction, and self-rated team output.

$\mathrm{H6}$ : The positive relationships predicted in $\mathrm{H} 5$ will be significantly stronger for participants in the interprofessional group condition, compared to the uni-professional group condition.

\section{MATERIALS AND METHODS \\ Methodology/Research Design}

Students, ranging from 18 to 25 years old, enrolled in a therapeutic modalities course were included in this analysis. A sample of 90 physical therapy students and 22 athletic training students were randomly divided into 36 three-to-four person groups, such that 18 groups consisted of only PT students and 18 groups consisted of both PT and AT students. Gender, ethnicity, and other demographic factors of students enrolled in the course were consistent with the larger student population at Saint Louis University.

Students in this course were in their first professional year of their respective program. The Athletic Training Program utilizes an integrated approach to clinical education where students are engaged concurrently in didactic coursework and clinical practica. Thus, the AT students were provided with exposure to course content in a clinical context while engaged in the course. The Program in Physical Therapy utilizes an immersive approach to clinical education where the PT students were enrolled in only didactic coursework. The PT students in this course had not yet begun clinical practica, the first of which will take place in the following year. Thus, the AT and PT students learned about the course material in differing clinical contexts.

Although our sample was composed of all students, we expected that students were generally at a point in their professional training programs that they would have already internalized the most salient aspects related to their role and responsibilities of their professional identity. Furthermore, we expected that students would behave in such a way that reflected their particular professional identity (e.g., AT vs. PT), which would, in turn, facilitate the learning process across professional boundaries. That is, we expected that the behaviors exhibited by students would be aligned with their professional identities, and that those behaviors would be the main source of knowledge from which students derived information about each other's roles (i.e., interprofessional role clarity).

\section{Study Intervention}

The course in therapeutic modalities is part of the required curriculum for the graduate level Master's in Athletic Training and Physical Therapy Doctorate Programs. For both groups of students, the course was taken during the first professional phase year in the program and after completing three years of undergraduate coursework. The course consisted of two 50-minute lecture sessions per week, and all students participate in one of four, two-hour lab sections per week. The course was taught by an interprofessional teaching team consisting of an athletic trainer as the course director, physical therapist as the lab coordinator, and two athletic trainers as lab instructors. 
Case-based learning activities, in which students work together in teams, were implemented during lecture sessions at four time points throughout the semester. Students were separated into 18 interprofessional (IP) and 18 uni-professional (UP) teams of three-to-four members per team. The activities took place in a lecture hall where teams were assigned locations to sit together to ensure adequate space for all. Students were free to roam during this time; however, they were instructed to work within their assigned teams. Teams could ask questions of the course director as needed.

The case-based learning activities consisted of simulated patient cases that included patient history, presentation, and goals. Students were asked to document appropriate therapeutic interventions including main outcomes, assessment methods, physiological effects, contraindications, precautions, and parameters. Teams of students were given one of six cases that reflected course content covered up to that point in the term. Teams spent approximately 30 minutes completing the assignment followed by ten minutes of facilitated discussion by the course director. A total of four case-based learning activities were completed over the course of the semester, occurring an average of four weeks apart. An example of one of the case studies is as follows:

"A 34-year-old female presents with a diagnosis of chronic elbow tendinosis and complains of right lateral elbow pain and stiffness that she attributes to tennis activities. Exam reveals pain with palpation at the common wrist extensor tendon at the lateral elbow, pain and weakness with resisted wrist extension, and decreased active and passive range of motion (A/PROM) wrist flexion. Primary Medical History (PMHx): currently four months pregnant with gestational hypertension (HTN)."

\section{Measures}

The Role Clarity/Ambiguity Scale developed by Rizzo, House, and Lirtzman was used to assess role clarity across professional boundaries. ${ }^{13}$ This instrument has been shown to exhibit desirable psychometric properties across multiple studies. ${ }^{14-16}$ This study used the four items included by Mukherjee and Malhotra presented on a seven-point Likert-type scale ranging from $1=$ Strongly Disagree to 7 = Strongly Agree..$^{17}$ In line with the overarching purpose of the study, the items were adopted such that respondents were asked to report the extent to which they are clear regarding the roles of the others, rather than their own role (e.g. AT students reported on the role of PT and PT students reported on the role of AT). The estimate of internal consistency obtained in our sample was acceptable for the pre-test $(\alpha=.94)$, post-test $(\alpha=.94)$, and the retrospective pre-test $(\alpha=.96)$.

Perceptions of team viability were assessed at the individual level using the Team Viability Scale originally developed by Hackman and subsequently used by Lewis. ${ }^{10,18}$ The scale includes three items presented on a seven-point Likert-type scale ranging from 1 $=$ Strongly Disagree to $7=$ Strongly Agree. The items ask about perceptions regarding the extent to which individuals perceive the long-term potential for their team to work together. The estimate of internal consistency obtained in our sample was acceptable for the pre-test $(\alpha=.95)$.

Perceptions of team member satisfaction were assessed at the individual level using the Team Member Satisfaction Scale originally developed by Hackman and subsequently used in Foo, Sin, and Yiong. ${ }^{10,19}$ The scale includes three items presented on a sevenpoint Likert-type scale ranging from $1=$ Strongly Disagree to $7=$ Strongly Agree. The items ask about perceptions regarding the extent to which individuals were satisfied working within their team. The estimate of internal consistency obtained in our sample was acceptable $(\alpha=.73)$.

Four single-item measures were created for the purposes of exploratory analyses. One item, presented on a seven-point Likerttype scale ranging from $1=$ Strongly Disagree to 7 = Strongly Agree, was created to assess the extent to which respondents were satisfied with their team's output. Three additional items were created in which each respondent was asked to rate their team's case study responses on accuracy, reasoning, and thoroughness. These items were presented on a seven-point scale ranging from $1=$ Very Poor to 7 = Very Good. Items for all measures are included in Appendix A.

\section{Data Collection}

All student participants were recruited via in-class announcements. The case-based learning activities and the assessment tools were embedded into the course structure. At the start of the semester, all students were asked to complete a role clarity scale to assess their perceptions of roles across professional boundaries. Students then engaged in four case-based learning activities with their assigned teams. After all four activities were completed, students were again asked to complete the role clarity scale, along with a team viability scale, and a team member satisfaction scale. Students were also asked to complete a retrospective pretest assessing their perceptions of role clarity across professional boundaries. We chose to include a retrospective pre-test measure along with the actual pre-test to account for any reference shift that may occur as a result of an increased understanding of the breadth and depth of the subject matter in question. 
The completed assignments from the case-based learning activities were also evaluated by an instructor for quality in terms of accuracy, reasoning, and thoroughness, and used as an index of group effectiveness. These evaluations were only used for purposes of the study, had no bearing on student grades, and were not shared with students. Lastly, students provided a written reflection of their experiences as a course assignment that was later evaluated for themes related to IPEC Core Competencies of Interprofessional Collaborative Practice. This information will be reported in a separate manuscript.

All students enrolled in the course received a comprehensive syllabus outlining the course objectives, expectations, and other pertinent information related to the course. Students were notified that participation was completely voluntary, and that they had the option to have their assignment information excluded from the research study. No participants requested that their information be withheld. All survey responses and reports were de-identified, such that longitudinal and group level analysis were conducted using four digits codes unique to each individual.

\section{Data Analysis}

All statistical analyses were conducted using R Programming Language for Statistical Computing. ${ }^{20}$ To test $\mathrm{H} 1$ and $\mathrm{H} 2$ that predicted differences between pre-test and post-test role clarity scores, and differences between retrospective pre-test and posttest role clarity scores, a repeated measures ANOVA was conducted using Type III Sum of Squares calculations. This test examines the effect that the intervention had on participants' role clarity, regardless of team condition.

To test $\mathrm{H} 3$ and $\mathrm{H} 4$ that predicted differential changes in role clarity between experimental (IP) and control (UP) conditions, repeated measures ANOVA models were tested on each condition using Type III Sum of Squares calculations. This test examines the main effect of the team condition on participants' role clarity. Descriptive statistics are presented in Tables 2 and 3 , respectively.

The following set of analyses test our last two hypotheses by examining the relationships between interprofessional role clarity and perceptions of group effectiveness, as well as the extent to which these relationships differ across our intervention conditions. Correlations were examined to test $\mathrm{H} 5$ that predicted positive relationships between interprofessional role clarity, perceptions of team viability, individual team member satisfaction, and self-rated team output. To test $\mathrm{H} 6$, in which it was predicted that the relationships described in $\mathrm{H} 5$ would be significantly stronger for the individuals in the IP condition (compared to participants in the UP condition), a multivariate moderated regression model was constructed and tested. The decision to treat the three dependent variables team viability, team member satisfaction, and self-rated team performance as a multivariate (i.e. a single composite variable) was based on our underlying theoretical framework which stipulates that all three, together, compose the overarching construct of group effectiveness.

\section{Ethical Considerations}

This study was approved by the Institutional Review Board of Saint Louis University (FWA00005304).

\section{RESULTS}

Response invariance was assessed and used as an indicator of insufficient effort in responding. Three respondents were identified with zero variance in their responses (i.e. provided the exact same response for all items) and were excluded from all subsequent analyses. Respondents with missing data for any of the three data collection points (pre-test, post-test, and retrospective pre-test) were excluded from subsequent analysis. Data were first assessed for univariate outliers (z-score greater than 3 ) and multivariate outliers (Cook's distance four times greater than the mean) with analyses grouped by team condition. In total, four outlier cases were identified, and were excluded from subsequent analyses. Descriptive statistics and correlations are presented in Table 1.

Table 1. Descriptive Statistics

\begin{tabular}{|c|c|c|c|c|c|c|}
\hline & \multirow[b]{2}{*}{$N$} & \multirow[b]{2}{*}{$M$} & \multirow[b]{2}{*}{$S D$} & \multicolumn{3}{|c|}{ Correlations } \\
\hline & & & & 1 & 2 & 3 \\
\hline 1 Pre-test role clarity & 73 & 5.23 & 1.19 & 1 & & \\
\hline 2 Post-test role clarity & 73 & 5.04 & 1.31 & $.45^{\star *}$ & 1 & \\
\hline 3 Retrospective pre-test role clarity & 73 & 4.85 & 1.42 & $.42^{* *}$ & $.90^{* *}$ & 1 \\
\hline
\end{tabular}




\section{Pre versus Post Comparisons}

Results from the repeated measures ANOVA suggests a significant difference exists between time points, albeit with a negligible generalized effect size $\left(F(2,144)=3.76, p=0.03, \eta^{2}=0.014\right)$. Results also suggest that the assumption of sphericity was violated as Mauchly's test was significant $(p<.001)$. Based on follow up tests $(\varepsilon=.65)$, the Greenhouse-Geisser correction was applied, which yielded an adjusted $p$-value $(p=0.04)$.

Based on the results from the omnibus test, it was appropriate to conduct post-hoc analyses to determine which means were significantly different. Post-hoc analyses were conducted using a Bonferroni correction to adjust derived $p$-values based on multiple comparisons. Results from post-hoc analyses suggest no significant difference between pre-test role clarity scores and post-test role clarity scores ( $p=0.70, d=0.15,95 \% \mathrm{Cl}[-0.08,0.38])$, and no significant difference between pre-test role clarity scores and retrospective pre-test role clarity scores $(p=0.08, d=0.14,95 \% \mathrm{Cl}[-0.09,0.37])$. A significant difference was found between retrospective pre-test role clarity scores and post-test role clarity scores with a small effect size $(p=0.03, d=0.29,95 \% \mathrm{Cl}[0.05$, $0.52])$.

Overall, results do not support $\mathrm{H} 1$, and suggest that no significant reference shift (i.e. gamma change) occurred between pre-test scores and retrospective pre-test scores. However, results do support $\mathrm{H} 2$, and suggest a significant difference between retrospective pre-test scores and post-test scores, albeit with a small effect size. Taken together, the extent to which interprofessional role clarity was enhanced by the case-based learning experiences is unclear.

\section{Pre versus Post Comparisons between Team Conditions}

Descriptive statistics and correlations for both IP and UP groups are presented in Tables 2 and 3 , respectively. Results suggests no significant difference between time points for either the experimental condition or the control condition, $\left(\mathrm{F}_{\exp }(2,70)=1.88, p=\right.$ $\left.0.16, \eta^{2}=0.015 ; F_{\text {con }}(2,72)=1.90, p=0.16, \eta^{2}=0.012\right)$. Therefore, it was inappropriate to conduct any follow up analyses examining pairwise differences. Results do not support the predictions made in $\mathrm{H} 3$ or $\mathrm{H} 4$.

Table 2. Descriptive statistics for interprofessional condition

\begin{tabular}{|c|c|c|c|c|c|c|}
\hline & \multirow[b]{2}{*}{$N$} & \multirow[b]{2}{*}{ M } & \multirow[b]{2}{*}{$S D$} & \multicolumn{3}{|c|}{ Correlations } \\
\hline & & & & 1 & 2 & 3 \\
\hline 1 Pre-test role clarity & 36 & 5.23 & 1.14 & 1 & & \\
\hline 2 Post-test role clarity & 36 & 5.00 & 1.49 & .30 & 1 & \\
\hline 3 Retrospective pre-test role clarity & 36 & 4.81 & 1.55 & $.36^{*}$ & $.94^{* *}$ & 1 \\
\hline
\end{tabular}

Table 3. Descriptive statistics for uni-professional condition

\begin{tabular}{|c|c|c|c|c|c|c|}
\hline & \multirow[b]{2}{*}{ N } & \multirow[b]{2}{*}{ M } & \multirow[b]{2}{*}{$S D$} & \multicolumn{3}{|c|}{ Correlations } \\
\hline & & & & 1 & 2 & 3 \\
\hline 1 Pre-test role clarity & 37 & 5.22 & 1.25 & 1 & & \\
\hline 2 Post-test role clarity & 37 & 5.08 & 1.13 & $.64^{* *}$ & 1 & \\
\hline 3 Retrospective pre-test role clarity & 37 & 4.89 & 1.29 & $.48^{* *}$ & $.84^{* *}$ & 1 \\
\hline
\end{tabular}

\section{Interprofessional Role Clarity and Perceptions of Group Effectiveness}

Respondents with missing data were excluded from analysis and the assessment of univariate and multivariate outliers grouped by team condition were examined. In total, eight outlier cases were identified, and were excluded from subsequent analyses. 
Descriptive statistics and correlations for the entire sample, for the UP condition, and for the IP condition are presented in Tables 4,5 , and 6 respectively.

As shown in Table 4, results partially support $\mathrm{H} 5$ as interprofessional role clarity was positively related to both perceptions of team viability and self-rated team output, but not positively related to team member satisfaction.

Table 4. Descriptive statistics and correlations

\begin{tabular}{|c|c|c|c|c|c|c|c|}
\hline & \multirow[b]{2}{*}{$N$} & \multirow[b]{2}{*}{ M } & \multirow[b]{2}{*}{$S D$} & \multicolumn{4}{|c|}{ Correlations } \\
\hline & & & & 1 & 2 & 3 & 4 \\
\hline 1 Interprofessional role clarity & 77 & 5.06 & 1.31 & 1 & & & \\
\hline 2 Team viability & 77 & 6.39 & .58 & $.36^{* *}$ & 1 & & \\
\hline 3 Team member satisfaction & 77 & 6.35 & .66 & .14 & $.65^{\star *}$ & 1 & \\
\hline 4 Self-rated team output & 77 & 6.45 & .53 & $.35^{\star *}$ & $.80^{* *}$ & $.69^{* *}$ & 1 \\
\hline
\end{tabular}

Table 5. Descriptive statistics and correlations for uni-professional condition

\begin{tabular}{lccccccc}
\hline & $N$ & $M$ & $S D$ & 1 & 2 & 3 & \multicolumn{1}{c}{ Correlations } \\
\hline 1 Interprofessional role clarity & 38 & 5.08 & 1.11 & 1 & & & \\
2 Team viability & 38 & 6.34 & .62 & .27 & 1 & & \\
3 Team member satisfaction & 38 & 6.25 & .77 & .12 & $.64^{* *}$ & 1 & 1 \\
4 Self-rated team output & 38 & 6.39 & .55 & $.34^{* *}$ & $.84^{* *}$ & $.67^{* *}$ & \\
\hline
\end{tabular}

**. Correlation is significant at the .01 level (2-tailed).

*. Correlation is significant at the .05 level (2-tailed).

Table 6. Descriptive statistics and correlations for interprofessional condition

\begin{tabular}{|c|c|c|c|c|c|c|c|}
\hline & \multirow[b]{2}{*}{$N$} & \multirow[b]{2}{*}{$M$} & \multirow[b]{2}{*}{$S D$} & \multicolumn{4}{|c|}{ Correlations } \\
\hline & & & & 1 & 2 & 3 & 4 \\
\hline 1 Interprofessional role clarity & 39 & 5.03 & 1.50 & 1 & & & \\
\hline 2 Team viability & 39 & 6.44 & .55 & $.46^{\star *}$ & 1 & & \\
\hline 3 Team member satisfaction & 39 & 6.44 & .52 & .21 & $.79^{* *}$ & 1 & \\
\hline 4 Self-rated team output & 39 & 6.51 & .51 & $.40^{* *}$ & $.92^{* *}$ & $.71^{\star *}$ & 1 \\
\hline
\end{tabular}




\section{Differential Relationships Across Intervention Conditions}

The results of the multivariate moderated regression model suggest that only interprofessional role clarity significantly predicted perceptions of group effectiveness as shown in Table 7. The individual regression models for perceptions of team viability, team members satisfaction, and self-rated team performance are presented in Tables 8, 9, and 10 respectively. Results do not support any of the predictions made in $\mathrm{H} 6$.

\section{Table 7. MANOVA Summary}

\begin{tabular}{lcccc}
\hline Independent Variable & $d f$ & $F$ & $P$ & Pillai Trace \\
\hline Team condition & 1 & .67 & .57 & 0.03 \\
Post-test role clarity & 1 & 4.82 & $<.01^{* *}$ & 0.17 \\
Interaction & 1 & .29 & .83 & 0.01 \\
\hline
\end{tabular}

**. Correlation is significant at the .01 level (2-tailed).

*. Correlation is significant at the .05 level (2-tailed).

Table 8. Moderated regression for role clarity and team composition predicting team viability

\begin{tabular}{lcccccc}
\hline & \multicolumn{3}{c}{ Team_viability } & \multicolumn{3}{c}{ Team_viability } \\
\cline { 2 - 7 } & $B$ & $C l$ & $p$ & $B$ & $C l$ & $p$ \\
\hline (Intercept) & 5.52 & $5.00-6.04$ & $<.01$ & 5.58 & $4.73-6.42$ & $<.01$ \\
Team condition & .11 & $-.14-.36$ & .38 & .02 & $-1.03-1.07$ & .98 \\
Post-test role clarity & .16 & $.07-.26$ & $<.01$ & .15 & $-.01-.31$ & .07 \\
Interaction & & & & .02 & $-.18-.22$ & .86 \\
\hline Observations & & 77 & & & 77 & \\
$\mathrm{R}^{2} /$ adj. $\mathrm{R}^{2}$ & & $.14 / .12$ & & & $.14 / .11$ & \\
\hline
\end{tabular}

Table 9. Moderated regression for role clarity and team composition predicting satisfaction

\begin{tabular}{|c|c|c|c|c|c|c|}
\hline & \multicolumn{3}{|c|}{ Team_member satisfaction } & \multicolumn{3}{|c|}{ Team_member satisfaction } \\
\hline & $B$ & $\mathrm{Cl}$ & $p$ & $B$ & $\mathrm{Cl}$ & $p$ \\
\hline (Intercept) & 5.86 & $5.25-6.47$ & $<.01$ & 5.84 & $4.84-6.84$ & $<.01$ \\
\hline Team condition & .20 & $-.09-.50$ & .18 & .24 & $-1.01-1.49$ & .70 \\
\hline Post-test role clarity & .08 & $-.04-.19$ & .19 & .08 & $-.11-.27$ & .41 \\
\hline Interaction & & & & -.01 & $-.25-.23$ & .95 \\
\hline Observations & & 77 & & & 77 & \\
\hline$R^{2} /$ adj. $R^{2}$ & & $.05 / .02$ & & & $.05 / .01$ & \\
\hline
\end{tabular}


Table 10. Moderated regression for role clarity and team composition predicting performance

\begin{tabular}{|c|c|c|c|c|c|c|}
\hline & \multicolumn{3}{|c|}{ Self-rated team performance } & \multicolumn{3}{|c|}{ Self-rated team performance } \\
\hline & $B$ & $\mathrm{Cl}$ & $p$ & $B$ & $\mathrm{Cl}$ & $p$ \\
\hline (Intercept) & 5.65 & $5.19-6.12$ & $<.01$ & 5.56 & $4.80-6.32$ & $<.01$ \\
\hline Team condition & .12 & $-.10-.35$ & .27 & .27 & $-.68-1.21$ & .57 \\
\hline Post-test role clarity & .15 & $.06-.23$ & $<.01$ & .16 & $.02-.31$ & .03 \\
\hline Interaction & & & & -.03 & $-.21-.15$ & .76 \\
\hline Observations & & 77 & & & 77 & \\
\hline $\mathrm{R}^{2} /$ adj. $\mathrm{R}^{2}$ & & $.15 / .12$ & & & $.15 / .11$ & \\
\hline
\end{tabular}

\section{DISCUSSION}

The inclusion of both AT and PT students in this course offered a unique opportunity to implement an interprofessional experience directly into existing health professions curricula. In doing so, we assessed both the effect of a professional program course and case-based learning experiences on various measures of perceived group effectiveness. Our results share insights into how health professions programs might consider incorporating interprofessional case-based learning experiences throughout existing curriculum as a means of exposing learners to working in teams.

Results indicate that there was no reference shift in interprofessional role clarity as there was no significant difference between pre-test and retrospective pre-test role clarity. Although there was no significant difference between pre-test and post-test role clarity, the significant difference between retrospective pre-test and post-test role clarity provides at least some limited evidence that there was an overall course effect on improving interprofessional role clarity knowledge. Literature on the use of a retrospective pre-test suggests that these results often lead to less conservative estimates of true effect sizes, compared to traditional pre-test approaches..$^{21}$ Therefore, the actual effect of the course on role clarity may be slightly smaller than our results suggest. Nevertheless, our results offer some preliminary evidence to suggest that a shared professions course with case-based learning experiences may help students gain knowledge related to the roles of others across professional boundaries.

Separately examining IP groups and UP groups did not suggest that team composition was a contributing variable to the changes in role clarity. Results suggests that the changes in role clarity were a result of participating in the course, regardless of team composition. Although we attribute some of the gain in interprofessional role clarity knowledge to the participation in the casebased learning experiences, other factors may have contributed as well. For example, the course was instructed by an interprofessional teaching team comprised of three athletic trainers and one physical therapist. In both lecture and lab environments, instructors drew upon their individual professional experience to teach and demonstrate course curriculum. Students were therefore exposed to both athletic training and physical therapy professional roles through this shared instruction model, which may have contributed to improved interprofessional role clarity knowledge. While three of the four lab sections included in this course were uni-professional in composition, one lab did contain both AT (2) and PT (27) students. Lab work was completed in groups; therefore, these students had the opportunity to engage in interprofessional group work. Additionally, we were unable to control for any interprofessional interactions outside of the classroom.

Measures of perceived group effectiveness allowed us to examine how outcomes were related to role clarity. Role clarity was positively related to team viability and self-rated output. This may be explained by the gained knowledge and understanding of team members roles and responsibilities that contributes to sustainable and repeatable accomplishment of team goals, promoting team members to continue working together over time. Additionally, role clarity may be related to the quality of work outcomes. This is of particular interest as health care strives to improve quality health outcomes of populations. These team experiences may begin to expose health professions students to the positive relationship between team-based care and patient outcomes. ${ }^{22}$ However, it is important to note that the measure of quality output was self-reported. Results may differ if quality outcomes are evaluated by a third party or more objective measure. 
Descriptive statistics suggest there may be stronger relationships between role clarity and team viability and role clarity and selfrated output for those individuals that participated in IP teams. However, further analysis did not support that these relationships were meaningfully different across levels of team composition. Both IP and UP team's role clarity were related to self-rated output, but there was no significant difference in this relationship between groups. Team composition in these case-based learning experiences may not be a contributing factor to the relationship between role clarity and self-rated output.

\section{Limitations}

Limitations of this study include small sample size, which was restricted to course enrollment and impacted by response rate. Small sample size may have limited our ability to detect interaction effects of team composition and role clarity on perceptions of group effectiveness. Additionally, authors could not control for other interprofessional experiences occurring both within the course and outside the classroom that may have impacted the variables measured in this study. When considering the course effect on the entire sample, maturation of the students over the course of the semester may have posed a threat to internal validity. Quality output and role clarity were also self-reported. Results may be different if a more objective measure is used to assess these variables. For example, the quality of a group's work could be evaluated by an instructor, and role clarity could be determined by objectively asking students to identify specific roles and responsibilities of the other profession.

\section{Future Directions}

Much work can be done to further assess the impact of interprofessional activities in health professions curricula. Measures of group effectiveness at the group level could highlight the impact of role clarity on quality outcomes, specifically if quality is measured by more objective means. More could be learned regarding team member's experience with group activities through qualitative analysis.

\section{CONCLUSION}

Overall, our study examined the impact of IP and UP experiences built into a pre-existing shared health professions course. We learned that there is value in a course that provides opportunities for students to work together in case-based learning experiences. The extent of this value remains unclear, but results suggest that a course of this nature may have some impact on interprofessional role clarity, and role clarity has meaningful relationships with measures of perceived group effectiveness, particularly team viability and self-rated output.

Students in this course are just beginning their professional phase training of either athletic training or physical therapy education. Their exposure to other professions is usually limited at this early stage. The experience of interacting with one another in this course, including during case-based learning activities, may lead to increased knowledge of other's roles and responsibilities as shown in the retrospective pre-test and post-test role clarity differences. We suggest that health professions educators consider incorporating case-based learning activities into existing curricula in an effort to introduce other professions' roles and engage students in teamwork.

\section{Acknowledgements}

None.

\section{Declaration of Interest}

The authors report no conflicts of interest. The authors alone are responsible for the content and writing of this article.

\section{Funding}

None.

\section{REFERENCES}

1. Cruess RL, Cruess SR. Expectations and obligations: professionalism and medicine's social contract with society. Perspect Biol Med. 2008;51(4):579-598.

2. Klossner J. The role of legitimation in the professional socialization of second-year undergraduate athletic training students. Journal of athletic training. 2008;43(4):379-385.

3. JHV G, J Y, SJ H. A WHO report: framework for action on interprofessional education and collaborative practice. Journal of Allied Health. 2010;39:196-197.

4. Nelson S HB, Tassone M,. Creating the health care team of the future: the Toronto model for interprofessional education and practice. Ithaca, NY: ILR Press; 2014. 
5. Shoemaker MJ, Platko CM, Cleghorn SM, Booth A. Virtual patient care: an interprofessional education approach for physician assistant, physical therapy and occupational therapy students. J Interprof Care. 2014;28(4):365-367.

6. Trommelen RD, Hebert L, Nelson TK. Impact on physical therapy and audiology students of an interprofessional casebased learning experience in education of vestibular disorders. Journal of Allied Health. 2014;43(4):194-200.

7. Lairamore C, Morris D, Schichtl R, et al. Impact of team composition on student perceptions of interprofessional teamwork: A 6-year cohort study. Journal of Interprofessional Care. 2018;32(2):143-150.

8. Lockeman KS, Lanning SK, Dow AW, et al. Outcomes of introducing early learners to interprofessional competencies in a classroom setting. Teaching and learning in medicine. 2017:1-11.

9. Khalili $\mathrm{H}$, Orchard $\mathrm{C}$, Laschinger HK, Farah R. An interprofessional socialization framework for developing an interprofessional identity among health professions students. JOURNAL OF INTERPROFESSIONAL CARE 27(6):44845. 2017.

10. Hackman JR. The design of work teams. In: Lorsch J, ed. Handbook of organizational behavior. Englewood Cliffs, NJ: Prentice-Hall; 1987.

11. Onyura B, Baker L, Cameron B, Friesen F, Leslie K. Evidence for curricular and instructional design approaches in undergraduate medical education: An umbrella review. Medical teacher. 2016;38(2):150-161.

12. Colgrove YM, VanHoose LD. DPT Student perceptions of the physical therapist assistant's role: effect of collaborative case-based learning compared to traditional content delivery and clinical experience. J Allied Health. 2017;46(1):1-9.

13. Rizzo JR, House RJ, Lirtzman SI. Role conflict and ambiguity in complex organizations. Administrative Science Quarterly Jun70.15(2):150.

14. Schuler RS, Aldag RJ, Brief AP. Role conflict and ambiguity: a scale analysis. Organizational Behavior \& Human Performance Oct77.20(1):111.

15. Teas KR, Wacker JG, Hughes ER. A path analysis of causes and consequences of salespeople's perceptions of role clarity. Journal of Marketing Research. 1979;16(3).

16. Kelloway EKQsU, Kingston, ON, Canada, Barling J. Item content versus item wording: Disentangling role conflict and role ambiguity. Journal of Applied Psychology.

17. Mukherjee A, Malhotra N. Does role clarity explain employee-perceived service quality?: A study of antecedents and consequences in call centres. In: International Journal of Service Industry Management (International Journal of Service Industry Management.

18. Lewis K. Knowledge and performance in knowledge-worker teams: a longitudinal study of transactive memory systems. Management Science 50(11):1519-153.

19. Foo MD, Sin HP, Yiong LP. Effects of team inputs and intrateam processes on perceptions of team viability and member satisfaction in nascent ventures. STRATEGIC MANAGEMENT JOURNAL 27(4):389-39.

20. R: A language and environment for statistical computing [computer program]. Vienna, Austria: R Foundation for Statistical Computing; 2008.

21. Pratt CC, Mcguigan WM, Katzev AR. Measuring program outcomes: Using retrospective pretest methodology. In: American Journal of Evaluation (American Journal of Evaluation.

22. World Health Organization. Framework for action on interprofessional education and collaborative practice. Geneva: WHO;2010. 